\title{
EFFECTS OF SOCIO-CULTURAL FACTORS ON \\ EFFECTIVE AGRICULTURAL TRAINING PROGRAMS FOR FARMERS BY THE BENUE STATE AGRICULTURAL DEVELOPMENT AUTHORITY IN ZONE C
}

\author{
Simon Ameh Ejembi ${ }^{*}$ and Hephzibah Onyeje Obekpa² \\ ${ }^{1}$ Department of Agricultural Extension and Communication, College of Agricultural \\ Economics and Extension, University of Agriculture, Makurdi, Nigeria. \\ ${ }^{2}$ Department of Agricultural Economics, College of Agricultural Economics And Extension, \\ University of Agriculture, Makurdi, Nigeria. \\ ${ }^{*}$ Corresponding author: E-mail: amesimon72@gmail.com
}

Citation: Ejembi, S.A., Obekpa, H. O., 2017. Effects of Socio-Cultural Factors on Effective Agricultural Training Programs for Farmers by the Benue State Agricultural Development Authority in Zone C. J. Asian Rur. Stud. 1(1): 60-69

\begin{abstract}
Most agricultural innovations were not sustainably adopted due to incompatibility to social and cultural practices. Based on this proposition, this study was designed to analyze the effects of socio-cultural factors on agricultural training programs for farmers by the Benue State Agricultural and Rural Development Authorities (BNARDA) for farmers in Zone C. Seven communities were purposively selected due to their unique cultural practices and a total of 118 respondents were randomly selected for the study. Questionnaire was used as tool for data collection. Descriptive statistics and logit regression were used for data analysis. The results show that there were $22 \%$ of respondents aged between 50-60 years, $72 \%$ of them were married and about $60 \%$ had at least secondary educational attainment. Annual income of respondents was between $\$ 80,000.00$ - $\$ 100,000.00$. About $72 \%$ had farming experience of less than 10 years, and $31 \%$ were cosmopolites. The result further shows that fear of ostracization was among the major reasons that inhibit training program participations. The results of logit analysis show that education (-3.3987), gender (2.268), rivers/streams (-.732) and leadership (2.150) were significantly affect training program. It was concluded that farmer who have strong cultural beliefs were responsible for non- participation in the training program. It was recommended that aggressive advocacy program be embarked by BNARDA before packaging a training program for the farmers.
\end{abstract}

Keywords: Socio-Cultural; Training Program; Farmer; Benua State 


\section{Introduction}

Though most of the foods in Nigeria are produced by subsistence farmers, the demand for food outstrip the supply and Nigeria still depends on importation of certain food crops (Ojo, 1991; Obadan, 1997). The availability of a sustainable agricultural technology for Nigerian -poor resource farmers is important for the country's effort in achieving food security (Ladebo, 2004). It is known to everyone that government has made much effort in boosting agricultural production. Among these efforts made is the establishment of various agricultural research institutes in Nigeria. The product of the findings of these institutes was disseminated to the farmers through the extension agents.

According to FAO (2001), agriculture and rural extension are one of the means available to help alleviate poverty and improved food security. The goal of extension is to ensure that increased agricultural productivity is achieved by stimulating farmers to use modern and scientific production technologies developed through research.

The performance of Nigerian agriculture so far indicated that the farmers have neither used nor absorbed most of the technologies being introduced to them (Ejembi, 2009). This was attributed to the fact that most farmers fear trying improved technologies because they did not have the necessary financial resources to adopt the technologies. This was partly explained by the fact that most agricultural technologies require complementary inputs such as fertilizers and pesticides. These complementary inputs were difficult to come by due to the cash trapped nature of farmers (Idrisa and Ogunbameru, 2008). The use of agricultural technologies was believed as a strategy for making small-scale farmer as economically viable units. However, researches have shown that the cultural factors effect the acceptance of diffusion of new technologies. It was discovered that the adoption of information technology products was not fully understood, partially because of the lack of fit between technology and culture (Kalliny and Hausman, 2007).

Cultural factors are leading constraints to the effectiveness of extension work. In some cultures, access to certain products may not be possible in local markets and, therefore, adoption of such products may be difficult and slow. Language according to Macionis and Plummer (2005), was the key to the world of culture and a system of symbols that allows members of a society to communicate with one another. They posit that these symbols take the form of spoken and written words, which were culturally variable and composed of the various alphabets and ideograms used around the world. Although language differences can impede the communication of improved technology unless they are taken into account, it was the major means of cultural reproduction which was the process through which one generation passes culture to the next (Macionis and Plummer, 2005). The division between the sex influences the nature of farming systems since most men were employed off-farm, they leave most farm operations to the women. Values and goals were closely related to individual farmer's attitudes and motivation. Macionis and Plummer (2005), supports this as he posited that in technologically simple societies of the past, women produced more food than men. As such, where the norms of the community were favorably disposed towards change, adoption is more likely to occur. Also, institutional characteristics like land tenure system, social system, affect the prevalent values and norms of the community and 
these in turn, affect the behavior of individual farmers with respect to technological changes (Reeve, 1998).

In any society, members usually occupy or are perceived to belong to certain social categories. These categories may be referred to as statuses, which can be as a result of occupation, family lineage and gender (Haralambos et al., 2004). Some of these statuses maybe culturally defined and relatively fixed and there was little individuals can do to change their assignment to particular social positions such as gender, aristocratic titles and all ascribed statuses. Achieved statuses were entered into as a result of some degree of purposive action and choice (Haralambos et al., 2004).

As the food situation and the performance of the agricultural sector worsened, a number of agricultural programs and projects were launched. From the early 1970s, Nigeria registered a decline in agriculture and food sector output as a result of the gross neglect of agriculture following the focus on the oil sector (Ibrahim and Oyewole, 2010). Many interventions aimed at increasing domestic food production and food availability were initiated. These include Operation Feed the Nation (OFN), Green Revolution, Directorate of Food, Road and Rural Infrastructure (DFRRI) and Better Program (Ibrahim and Oyewole, 2010).

With all these in place, agricultural outputs has remained low, farmers farming techniques have also remained obsolete in the study area. The question now relates to whether the low level technology application or usage in the study area has been due to the socio-cultural factors. Therefore, this study was set out to analyze the effect of socio-cultural factors on effective agricultural training programs in Zone $\mathrm{C}$ of Benue Agricultural Development Authority (BNARDA). To be more specific this study examine the socio-cultural characteristics of farmers in the study area; identify some cultural factors that may inhibit successful training in the area; and determine the effects of the cultural factors on effective capacity building.

\section{Method}

The study was conducted in Zone C Area of Benue State. Seven communities (Agwangwe, Anmoda, Akpoga, Ojapo, Olaidu, Ingle and Ipoya) were purposively selected due to their unique cultural activities and 118 respondents were selected using simple random sampling technique. Data were collected by administering a structured questionnaire to 118 farmers in the selected communities. However, only 115 copies of questionnaire were correctly completed and returned for use in the analysis. Table 1 show the summary of the population and sample size.

Percentages were used to analyze the data on the socio-cultural characteristics of respondents and the identified socio-cultural factors. Logit regression was employed to determine the effects of selected socio-cultural factors on effective agricultural development training programs. The logit regression model is a binary choice technique, which allows for prediction of socio-cultural variables on adoption decisions (Falusi, 1974). This model is based on the fact that the effect of socio-cultural factors on effective agricultural development training programs can be considered to be dichotomous. The nature of the dichotomy means that there is a threshold in the dimension of the explanatory variables (socio-cultural factors) below which no positive response will be elicited (Bamire and Olubode, 2001). 
Table 1. Summary of the Population and the Sample Size

\begin{tabular}{llcc}
\hline No & Communities & $\begin{array}{c}\text { Population of farm } \\
\text { families }(\mathbf{X})\end{array}$ & $\begin{array}{c}\text { Sample size } \\
(\mathbf{1 5 \%} \text { of } \mathbf{X})\end{array}$ \\
\hline 1 & Agwangwe & 70 & 11 \\
2 & Akpoga & 89 & 13 \\
3 & Anmoda & 75 & 11 \\
4 & Ingle & 131 & 12 \\
5 & Ipoya & 79 & 12 \\
6 & Ojapo & 145 & 22 \\
7 & Olaidu & 191 & 29 \\
& & $\mathbf{7 8 0}$ & $\mathbf{1 1 8}$ \\
\hline
\end{tabular}

According to Manyong and Houndekon (1997), it is only when the threshold level is reached that a positive response can be observed. In the dummy variable models, such as the probit and logit, the logit model is chosen as the best approach used for interpreting the effect of qualitative socio-cultural factors because it does not necessitate the transformation of data. The values of prediction are such that;

$\mathrm{Pi}=1$ when $\alpha+\beta \mathrm{Xi} \leq 1$

$=0$ when $\alpha+\beta \mathrm{Xi} \geq 0$

However, it is possible to obtain values for $\alpha$ and $\beta$ using maximum-likelihood estimation (MLE). The use of MLE guarantees that the parameter estimates will be consistent and the appropriate statistical tests can be performed. This means that all the parameter enumerators are asymptotically normal, such that test of significance analogous to the regression t-tests can be performed.

Although the stimulus level and corresponding probability are unobservable, the effect or non-effects of some particular socio-cultural factors are known. Hence, the likelihood function can be defined under the additional specification that the observations are statistically independent of each other. That is, the probability of a particular socio-cultural factor possibly affecting decision of farmers is dependent on the level of his stimulus, which is in turn a function of his explanatory variables (Bamire and Olubode, 2001). The logit model is of the form;

$\mathrm{Z}=\mathrm{a}+\mathrm{b}_{1} \mathrm{X}_{1}+\mathrm{b}_{2} \mathrm{X}_{2}+\mathrm{b}_{3} \mathrm{X}_{3}+\ldots . .+\mathrm{b}_{\mathrm{n}} \mathrm{X}_{\mathrm{n}}$

Where $\mathrm{Z}=$ Stimulus which cannot be observed but is defined as linear combination of the observable variables. It can be represented for the ith characteristics as;

$\mathrm{Z}=\mathrm{B}_{1} \mathrm{X}_{1} \mathrm{i}+\mathrm{B}_{2} \mathrm{X}_{2} \mathrm{i}+\mathrm{B}_{3} \mathrm{X}_{3} \mathrm{i}+\ldots \ldots+\mathrm{B}_{\mathrm{n}} \mathrm{X}_{\mathrm{ni}}$

$\mathrm{Xs}=$ Socio-cultural factors of the farmers, $\mathrm{I}=1,2,3 \ldots \mathrm{N}$

The $\mathrm{Z}$ can also be referred to as the adoption equation in the context of this study. The relationship between the stimulus level $(Z)$ and the socio-cultural characteristics follow a sigmoid shape. Whereas, the probability cannot take on values outside $0-1$ range, the stimulus can take on any value of the entire real scale $(-\infty$ and $-\infty)$. The expected signs of the coefficients of the socio-cultural factors will be predicted 'a priori', based on past studies, economic theory and logical reasons. Most of the independent variables will be expected to be highly significant in the prototype model at $\mathrm{P} \leq 0.1$. Model specification in this study was 
$Z=$ effective agricultural development training programs; $X_{1}=$ age; $X_{2}=$ sex; $X_{3}=$ social status; $\mathrm{X}_{4}=$ beliefs; $\mathrm{X}_{5}=$ educational status; $\mathrm{X}_{6}=$ shrines/river; $\mathrm{X}_{7}=$ marital status.

\section{Results and Discussions}

\subsection{Social Characteristics of Respondents}

The selected social characteristics of respondents considered relevant for this study were; age, sex, educational status, annual income, farm size, farming experience, household size, social status and cosmopolitness.

As shown in Table 2, that there were $27.0 \%$ of the respondents belongs to age bracket of 30.1-40 years. This indicated that the age structure of the farmers in the study area was dominated by young and active farmers who are capable of performing most of the farm operations by themselves, and because people within this age category are considered energetic and venturesome, consequently, may be willing to adopt and use new farm practices. This finding supported by Rogers (2004), who stated that the younger the farmer is, more likely to adopt innovations early in his or her respective life cycle.

Table 2. Distribution of Respondents According to Their Social Characteristics $(\mathrm{N}=115)$

\begin{tabular}{|c|c|c|}
\hline Characteristics & Frequency & Percentage \\
\hline \multicolumn{3}{|l|}{ Age (years) } \\
\hline $20.0-30$ & 21 & 18.3 \\
\hline $30.1-40$ & 31 & 27.0 \\
\hline $40.1-60$ & 19 & 16.5 \\
\hline $50.1-60$ & 26 & 22.6 \\
\hline $60.1-70$ & 15 & 13.0 \\
\hline $70.1-80$ & 3 & 2.6 \\
\hline Total & 115 & 100.0 \\
\hline \multicolumn{3}{|l|}{ Sex } \\
\hline Female & 22 & 19.1 \\
\hline Male & 93 & 80.9 \\
\hline Total & 115 & 100.0 \\
\hline \multicolumn{3}{|l|}{ Marital status } \\
\hline Single & 20 & 17.4 \\
\hline Married & 83 & 72.2 \\
\hline Widowed & 7 & 6.1 \\
\hline Divorced & 3 & 2.6 \\
\hline Separated & 2 & 1.7 \\
\hline Total & 115 & 100.0 \\
\hline \multicolumn{3}{|l|}{ Educational qualification } \\
\hline No formal education & 24 & 20.9 \\
\hline Primary & 24 & 20.9 \\
\hline Secondary education & 30 & 26.1 \\
\hline Sub-Degree & 37 & 32.2 \\
\hline Total & 115 & 100.0 \\
\hline
\end{tabular}




\begin{tabular}{|c|c|c|}
\hline \multicolumn{3}{|l|}{ Occupation } \\
\hline Civil servant & 15 & 13.0 \\
\hline Farming & 86 & 74.8 \\
\hline Trading & 14 & 12.2 \\
\hline Total & 115 & 100.0 \\
\hline \multicolumn{3}{|l|}{ Annual income } \\
\hline 20,000 and below & 21 & 18.3 \\
\hline $20,001-40,000$ & 31 & 27.0 \\
\hline $40,001-60,000$ & 19 & 16.5 \\
\hline $60,001-80,000$ & 26 & 22.6 \\
\hline $80,001-100,000$ & 15 & 13.0 \\
\hline 100,001 - and above & 3 & 2.6 \\
\hline Total & 115 & 100.0 \\
\hline \multicolumn{3}{|l|}{ Farm size (hectare) } \\
\hline $0.5-2.0$ & 6 & 5.2 \\
\hline $2.01-3.5$ & 14 & 12.2 \\
\hline $3.51-5.0$ & 24 & 20.9 \\
\hline $5.01-6.5$ & 8 & 7.0 \\
\hline $6.51-8.0$ & 10 & 8.7 \\
\hline $8.01-9.5$ & 6 & 5.2 \\
\hline 9.51 and above & 47 & 40.9 \\
\hline Total & 115 & 100.0 \\
\hline \multicolumn{3}{|l|}{ Farming experience (years) } \\
\hline Less than or equal to 10 & 83 & 72.2 \\
\hline $10.1-20$ & 20 & 17.4 \\
\hline $30.1-40$ & 6 & 5.2 \\
\hline 40.1 and above & 6 & 5.2 \\
\hline Total & 115 & 100.0 \\
\hline \multicolumn{3}{|l|}{ Household size } \\
\hline $1-5$ & 41 & 35.7 \\
\hline $6-10$ & 51 & 44.3 \\
\hline $11-15$ & 15 & 13.0 \\
\hline $16-20$ & 5 & 4.3 \\
\hline 21 and above & 3 & 2.6 \\
\hline Total & 115 & 100.0 \\
\hline \multicolumn{3}{|l|}{ Social status } \\
\hline Beaded Chief & 5 & 4.3 \\
\hline Honorary Chief & 1 & 0.9 \\
\hline Community Chief & 12 & 10.4 \\
\hline Opinion Leader & 12 & 10.4 \\
\hline Member of council of elders & 18 & 15.7 \\
\hline Lay member of the community & 67 & 58.3 \\
\hline Total & 115 & 100.0 \\
\hline
\end{tabular}




\begin{tabular}{lcc}
\hline Cosmopolitness & & \\
Do not travel at all & 5 & 4.3 \\
Once & 8 & 7.0 \\
$2-3$ times & 20 & 17.4 \\
$4-5$ times & 28 & 24.3 \\
$6-10$ times & 18 & 15.7 \\
$>10$ times & 36 & 31.3 \\
\multicolumn{1}{l}{ Total } & 115 & 100.0 \\
\hline
\end{tabular}

Farmer's population in the study area was predominance of men as indicated that $80.9 \%$ of the respondents were male. This population composition also has the advantage of independence as the men are usually the decision makers in a typical African setting.

Majority (72.2\%) of the respondents were married and it can be inferred based on this finding that the study area was dominated by married people with the task of making ends meet and providing for their families hence, the zeal to increase output. Consequently, this category of farmers may be more willing to adopt and use new farm practices.

Educational status of the respondents shown that $32.2 \%$ had sub-degree. This indicated that a high proportion of the respondents had attained one level of education or another. There was a positive implication of this on adoption decision. Most innovations were rejected or adopted on the basis of inadequate information or knowledge on the innovations' package. With over $80 \%$ respondents literate, it will simplify teaching and learning process of innovation. It will also make it possible for individuals to understand the values and or importance of technologies for their certain livelihood. This finding supported the findings of Weir and Knight (2000), that educated farmers were more likely to be successful adopters or innovations.

Occupational status of respondents revealed that majority $(90.4 \%)$ of the respondents were farmers who depended on farm as their major source of income. This implies that improved technologies are likely to be adopted so as to improve their standard of living. This agrees with Idrissa and Ogunbameru (2008), who stated that any sustainable innovation adopted by a majority of the respondents would positively affect living standards, especially if the innovation yields marketable products.

Annual income shows that many (27\%) of the respondents had annual income of between N20.0001-N40,0000. It can be inferred based on this finding that the economic status of farmers in the study area was low and these set of farmers will not have sufficient savings to purchase new technologies. The consequence is risk aversion. It is only logical for anyone who is poor to be risk aversive (Ejembi, 2009).

Farm size of respondents revealed that $40.9 \%$ of the them had farm size of 9.51 hectares and above. The fact that many of the respondents had up to 9.51 hectares of land means that the study area was dominated by farmers with large hectares of land, who may have the privilege of trying out innovations on small plot of their land to be certain of the benefits before full adoption.

Farming experience of respondents indicated that majority $(72.2 \%)$ of the respondents had farming experience of $<10$ years. This result reveals that the study area was a predominance of farmers who may be trading and consequently have not being in farming business for long. 
Household size of respondents revealed that $44.3 \%$ of the respondents had small household size of 6-10 members. This implies that, improved technologies are likely to be adopted since they are no available labour force. This finding is consistent with Oyewole, 2010) who found that the rate of adopted technology decreased as family size increased.

The result of social status reveals that majority $(58.3 \%)$ of the respondents were lay members of the community with low social status and prestige whose decisions are likely to be influenced by leaders of the community. The effect of this indicate that the real opinion of the people will not be known and this can lead to discontinued adoption when the people gain some influence and have opinion of their own. This finding disagree with the previous report of Kalliny and Hausuman (2007) that individual actors make decisions based on the previously made choices of other actors rather than on their own opinions.

The result of cosmopolitness reveals that $31.3 \%$ of the respondents had traveled more than 10 times. The result reveals that many $(31.3 \%)$ of the respondents had traveled so many times out of their community and had also interacted with members of other localities and as such, are more informed about new technologies. This is consistent with the finding of Ejembi (2009) that releases an individual from personal traditional opinions as the horizon of experience would have been broaden as a result of cross fertilization of ideas.

\subsection{Socio-Cultural Factors that may Inhibit Successful Training}

As shown in Table 3, the result of socio-cultural factors that may inhibit successful training shows that many $(19.8 \%)$ of the respondents were inhibited by fear of ostracization, $15.9 \%$ were inhibited by fear of mysterious disease infliction and those inhibited by engendering of ill fates, constitutes the least proportion $(9.5 \%)$ of the respondents. The import of the data above shows different degrees of fear of the unknown. This probably could be because there has not been any aggressive demonstration to the people that those beliefs would not have any effects on the people (Ejembi, 2009).

Table 3. Distribution of Respondents on the Basis of Their Perceptions of Some Social and Cultural Beliefs that Inhibits Participation in Training Programs

\begin{tabular}{lc}
\hline \multicolumn{1}{c}{ Constraints } & Frequency \\
\hline Fear of ostracization & 33 \\
Fear of possible death & 21 \\
Fear of mysterious disease infliction & 27 \\
Engendering of ill fates & 19 \\
Land tenure arrangements & 26 \\
Total & $\mathbf{1 2 6}^{*}$ \\
\hline
\end{tabular}

*=Multiple Responses 


\subsection{Effects of Socio-Cultural Factors on Effective Capacity Building}

In order to determine the effects of socio-cultural factors on effective capacity building, some selected socio-cultural factors were subjected to logic regression analysis and the results are presented in Table 4.

Table 4. Results of Logit Regression Analysis of Effects of Socio Cultural Factors on Effective Capacity Building $(\mathrm{N}=115)$

\begin{tabular}{lcccccc}
\hline \multicolumn{1}{c}{ Factors } & B & S.E. & WALD & Df & Sig. & Exp(B) \\
\hline Socio-Position & .121 & .221 & .303 & 1 & .582 & 1.129 \\
Education & -3.398 & 1.292 & 6.914 & 1 & $.009^{*}$ & .033 \\
Family Size & -.970 & 1.089 & .793 & 1 & .373 & .379 \\
Association & .197 & .922 & .046 & 1 & .831 & 1.218 \\
Interaction & .881 & .681 & 1.672 & 1 & .196 & 2.413 \\
Age & .348 & .838 & .172 & 1 & .678 & 1.416 \\
Gender & 2.268 & 1.093 & 4.305 & 1 & $.038^{*}$ & 9.657 \\
Shrine & -.325 & .727 & .200 & 1 & .655 & .722 \\
Sacred Forest & -.820 & 1.020 & .647 & 1 & .421 & .440 \\
Rivers & -.732 & 1.001 & 2.993 & 1 & $.084^{*}$ & .177 \\
Leadership & 2.150 & .685 & 9.861 & 1 & $.002^{*}$ & 8.505 \\
Religious belief & .209 & 743 & .079 & 1 & .779 & 1.232 \\
Farm size & 1.320 & .828 & 2.544 & 1 & .111 & 3.7443 \\
\hline
\end{tabular}

* = Significant at $10 \%$ Level of Probability

The data in Table 4 shows that education (-3.398), Gender (2.268), rivers (-.732) and leadership (2.150) were significant at $10 \%$ level of probability. It is noteworthy however that both the coefficient of educational status and the cultural beliefs that rivers are sacred, all have negative effects on adoption decisions. This result indicate that as people reduces their belief of rivers as sacred, there will be about $0.7 \%$ increase in adoption rate of the people; and that for every level of education acquired, there will be about $3.4 \%$ decrease in adoption rate. Ordinarily, the higher the educational attainment, the higher should the rate of adoption be but this is not the case here. This case may be due to the fact that as people become more educated, the likelihood to take to white colar jobs thereby, leaving farming at its traditional level will increase.

From the results of the Wald statistics, the leadership factor has the highest (about $98 \%$ ) individual contribution to adoption decision followed by education (69\%), then gender $43 \%$ and rivers as a culturally sacred place. This implies that if leadership becomes effective, then adoption rate will also increase.

\section{Conclusion}

The following conclusions were drawn based on the objectives of the findings of the study; Education and gender are the social factors that militate against adoption in the study area. The people are bound to their cultural beliefs which affect adoption process in the area. Also, people in the study area were inhibited by fear of the unknown and this affected their adoption decision. 


\section{Acknowledements}

We appreciate the authorities of the Federal University of Agriculture, Makurdi who gave us the privilege to carry out this study. We deeply appreciate Esther Abah who helped to coordinator the enumerators and finally Mrs. Sarah E. Ejembi for enduring my absence from home in the course of this study. We appreciate all authors whose materials we used as literature base for this study and to our respondents for prompt response and cooperation.

\section{References}

Bamire, A.S. and Olubode, O. (2001). "Socio-economic Determinants of Land Degradation in Osun State". In: Agricultural Economics in Nigeria, Proceeding of Association of Agricultural Economists, Nsukka, Nigeria: pp 212-217.

Ejembi, S.A. (2009). "Factors Affecting Community Resource Practice by Farmers in Okpokwu Local Government Area of Benue State". Unpublished Ph.D. Thesis. Submitted to the Department of Agricultural Economics and Rural Sociology, Ahmadu Bello University, Zaria. Pp. 25-27.

Falusi, A.O. (1974). 'Multivariate Probit Analysis of Selected Factors Influencing Fertiliser Adoption among Farmers in Western, Nigeria'. Nigeria. Journal of Economics and Social Studies 16(1):17-24.

Food and Agriculture Organization (FAO) (2005). "Dimitra Project - Rural Women and Development". www.fao.org/sd/dimitra.

Haralambos, M. Holborn, M and Heald, R. M. (2004). Sociology: Themes and Perspectives. New Delhi, India: Oxford University Press.

Idrisa, Y. L., Ogunbameru, B. O. and Ani, A. O. (2010). "Factors Affecting the Adoption of Improved Soybean Seeds in Southern Borno, Nigeria". Journal of Rural Development, Agricultural and Science, 1 (1): 1-10.

Kalliny, M. and Hausman, A. (2007). "The Impact of Cultrual and Religious Values on Consumer's Adoption of Innovation". www.freepatentsonline.com. Retrieved 07/02/2012.

Macionis, J. J. and Plummer, K. (2005) "Sociology: A Global Introduction. Third Edition, Pearson Education Limited, England. Pp.106, 109, 111.

Manyoung, V.M. and Houndekon, A.V. (1997). "Land Tenurial Systems and Adoption of Muccuna Planted Fallow in Derived Savannah of West Africa". Paper presented at the Workshop of Property Rights Collective Actions and Technology Adoption, Aleppo, Syria: ICARDA, pp. 10-14.

National Population Commission (NPC) (2006). Population Census. Abuja: Federal Republic of Nigeria Official Gazette, 94(24).

Oyewole, S. O. (2010). "Impact Assessment of the National Special Programme for Food Security in Nasarawa State, Nigeria". Journal of Rural Development, Agriculture, and Science. 1 (1): 114-125

Rogers, E. M. (2003) Diffusion of Innovations $5^{\text {th }}$ ed., New York: Free Press, CollierMacmillan Limited, London.pp.12, 15-16, 21, 229.

Weir, S. and Knight, J. (2000). Adoption and Diffusion of Agricultural Innovations in Ethiopia: The Role of Education. http://www.csae.ox.ac.uk/workingpapers/pdfd 20-05 text. pdf. Retrieved 15/08/2012. 